Andreas Franzmann / Barbara Wolbring (Hg.)

Zwischen Idee und Zweckorientierung

Vorbilder und Motive von Hochschulreformen seit 1945 
WISSENSKULTUR UND GESELLSCHAFTLICHER WANDEL

Herausgegeben vom Forschungskolleg 435

der Deutschen Forschungsgemeinschaft

»Wissenskultur und gesellschaftlicher Wandel«

Band 21 


\section{Zwischen Idee und Zweckorientierung}

Vorbilder und Motive

von Hochschulreformen seit 1945

Herausgegeben von

Andreas Franzmann und Barbara Wolbring

Akademie Verlag 
Gedruckt mit Unterstützung der Deutschen Forschungsgemeinschaft

Foto auf dem Einband: Universität Bochum, Foto: Oliver Schmidtke

Bibliografische Information der Deutschen Nationalbibliothek

Die Deutsche Nationalbibliothek verzeichnet diese Publikation in der Deutschen Nationalbibliografie; detaillierte bibliografische Daten sind im Internet über http://dnb.d-nb.de abrufbar.

ISBN 978-3-05-004308-1

(C) Akademie Verlag GmbH, Berlin 2007

Das eingesetzte Papier ist alterungsbeständig nach DIN/ISO 9706.

Alle Rechte, insbesondere die der Übersetzung in andere Sprachen, vorbehalten. Kein Teil dieses Buches darf ohne schriftliche Genehmigung des Verlages in irgendeiner Form - durch Photokopie, Mikroverfilmung oder irgendein anderes Verfahren - reproduziert oder in eine von Maschinen, insbesondere von Datenverarbeitungsmaschinen, verwendbare Sprache übertragen oder übersetzt werden.

Satz: Boris Slamka und Barbara Wolbring, Frankfurt/M.

Druck und Bindung: Druckhaus »Thomas Müntzer«, Bad Langensalza

Einbandgestaltung: Dorén + Köster, Berlin

Printed in the Federal Republic of Germany 